\title{
Geographical variation in bill size provides evidence for Allen's rule in a cosmopolitan raptor
}

\author{
Andrea Romano (i) | Robin Séchaud | Alexandre Roulin
}

Department of Ecology and Evolution, University of Lausanne, Lausanne,

Switzerland

\section{Correspondence}

Andrea Romano, Department of Ecology and Evolution, University of Lausanne, Building Biophore, CH-1015 Lausanne, Switzerland.

Email: andrea.romano@unil.ch

Funding information

Fondation du 450eme anniversaire;

American Natural History Museum;

Schweizerischer Nationalfonds zur

Förderung der Wissenschaftlichen

Forschung, Grant/Award Number:

31003A_153467; Basler Stiftung fur biologische Forschung; Fondation Agassiz,

Université de Lausanne; Akademie der

Naturwissenschaften

Editor: Brian Olsen/Brian McGill

\begin{abstract}
Aim: Avian beak morphology is a good example of how anatomical structures have evolved in response to different selective pressures, such as diet and vocalizations, but also thermoregulation. The last of these functions was neglected until recently, but convincing evidence has been provided regarding the capacity of birds to regulate heat dissipation through their highly vascularized bills. According to this adaptive function and coherently with the ecogeographical "Allen's rule", which predicts smaller body appendages in colder climates, large beaks should be favoured in warm environments. Here, we tested this prediction in the cosmopolitan common barn owl group.

Location: World.

Time period: $1809-2017$.

Major taxa studied: Tyto alba species complex.

Methods: We analysed the variation in bill length relative to body size according to temperature, latitude and elevation in 7,619 barn owls. The specimens were collected by 140 museums and represent three distinct evolutionary lineages that occur in geographically separated regions and cover the entire distributional range of the species complex: the Afro-Palaearctic Tyto alba, the Australasian Tyto javanica and the American Tyto furcata.

Results: In the three lineages, the bill becomes larger with increasing temperature. This convergent pattern of evolution of smaller bills in colder climates is associated with a latitudinal variation in temperature, because small-billed individuals occurred at higher latitudes than conspecifics living closer to the Equator. Moreover, in T. furcata, large-billed birds mostly occurred at lower elevations closer to the Equator, with bill length decreasing progressively with concomitant increase in latitude and elevation.
\end{abstract}




\section{1 | INTRODUCTION}

The size of the body and the proportions of its parts are probably the most important functional traits for living organisms, and they vary widely both within and among species (Chown \& Gaston, 2010; LaBarbera, 1989). How body size and proportions are determined by the climatic conditions prevailing in the environments where animals live have been the focus of many theoretical and empirical studies, even before Darwin (Allen, 1876; Atkinson \& Sibly, 1997; Bergmann, 1847; Mayr, 1956; Sheridan \& Bickford, 2011; Smith \& Lyons, 2011). The most influential study proposing a clear prediction about the distribution of body size along environmental gradients was published by Bergmann (1847). Known as "Bergmann's rule", it postulated that endotherms tend to be larger in colder climates compared with warmer habitats (Bergmann, 1847; see also Meiri, 2011; Olson et al., 2009; Salewski \& Watt, 2017). From a biophysical perspective, this pattern emerges because the lower surface-to-volume ratio of large individuals confers better heat retention for than smaller ones. The related "Allen's rule" (Allen, 1876) is instead focused on the size of the body extremities (relative to body size) according to the thermal environment. According to this rule, body appendages are expected to be smaller in colder climates (e.g., higher latitudes and elevations) because they prevent heat dissipation better. Geographical variation in the size of body appendages, such as limbs, tails, ears and bills, coherent with such a prediction have been observed frequently in many mammal and bird taxa (e.g., Fooden \& Albrecht, 1999; Friedman, Harmáčková, Economo, \& Remeš, 2017; Laiolo \& Rolando, 2001; Nudds \& Oswald, 2007; Symonds \& Tattersall, 2010). Nevertheless, exceptions to this rule have been reported (e.g., Stevenson, 1986).

Among the anatomical structures exclusive to birds, the beak size is an excellent example of how evolution has shaped morphology in response to a wide variety of selective pressures, including the prevailing diet, mate competition and vocalizations (Badyaev, Young, Oh, \& Addison, 2008; Grant \& Grant, 1995; Podos \& Nowicki, 2004; Smith, 1987; Willson, Karr, \& Roth, 1975). A function of the bill less appreciated until recent years is its role in thermoregulation (Tattersall, Arnaout, \& Symonds, 2017). However, an increasing number of studies are providing convincing evidence that avian beaks are functional heat-exchange surfaces used by birds to regulate the maintenance of body heat (Greenberg, Cadena, Danner, \& Tattersall, 2012; Scott, Cadena, Tattersall, \& Milsom, 2008; Tattersall, Andrade, \& Abe, 2009). It has been demonstrated that birds are able to increase or decrease the blood flow within the highly vascularized keratinaceous outer layer of the bill, the rhamphotheca, to regulate heat dissipation through its surface (Tattersall et al., 2009). In addition, they can behave actively to minimize exposure of the beak to lower ambient temperatures by attempting to insulate it with their plumage ("back rest behaviour"; Pavlovic, Weston, \& Symonds, 2019; Ryeland, Weston, \& Symonds, 2017). According to this adaptive function and coherently with "Allen's rule", large beaks should therefore be selected in warm environments, whereas the opposite is expected in cold climates.

Although geographical variation in bill size compatible with Allen's rule has been shown in comparative studies among different species (Campbell-Tennant, Gardner, Kearney, \& Symonds, 2015; Friedman et al., 2017; Symonds \& Tattersall, 2010) and at the within-species level on a continental scale (Danner \& Greenberg, 2015; Gehlbach, 2003; Greenberg, Cadena, et al., 2012; Greenberg, Danner, Olsen, \& Luther, 2012; Laiolo \& Rolando, 2001), comprehensive analyses on cosmopolitan species are still scant (Johansson, Linder, Hardin, \& White, 1998). The main aim of the present study is to examine whether the variation in bill size, relative to body size, is linked to temperature and geographical factors in the cosmopolitan common barn owl (Tyto alba) species complex. To this end, we used $>7,600$ specimens of the three distinct evolutionary lineages of this species complex, representing their entire range of distribution. Although their taxonomic status has yet to be elucidated fully (see Section 2.1), they can be considered as adaptive radiations occurring in different geographical regions and producing a large variety of local adaptations (see details described by Romano, Séchaud, Hirzel, \& Roulin, 2019; Uva, Päckert, Cibois, Fumagalli, \& Roulin, 2018): the Western (or Afro-European) barn owl, T. alba, the American barn owl, Tyto furcata, and the Eastern (or Australasian) barn owl, Tyto javanica. The investigation of this model system therefore provides the unique opportunity to compare traits among populations exposed to very different climatic and ecological conditions, and to disclose whether the same abiotic factors promoted the evolution of convergent traits in geographically separated regions.

Firstly, we examined whether bill size varies according to temperature in the manner predicted by Allen's rule. Secondly, we analysed whether the observed patterns in bill size can be explained by the two main geographical predictors strictly linked to temperature: latitude and elevation. Under a scenario of convergent evolution during concomitant adaptive radiations, we expected similar spatial patterns of body size variation among the three barn owl lineages.

\section{2 | METHODS}

\section{1 | Study system}

The common barn owl species complex is a group of nocturnal owls (König \& Weick, 2008; but see a notable exception in Bunn 1972) that inhabit all the continents, including most of the world's archipelagos, with Antarctica representing the only exception. The barn owl can live in a wide range of habitats, and it occurs across a huge latitudinal range (from c. $65^{\circ} \mathrm{N}$ to c. $55^{\circ} \mathrm{S}$ ). Very little information has been collected about the altitudinal range potentially exploited by barn owls. Although it has been suggested that at high latitudes it prefers to live at relative low elevations and that high mountain ranges might represent ecological barriers that limit its dispersal (e.g., the Rocky Mountains; Machado, Clément, Uva, Goudet, \& Roulin, 2018), it is also well known that this taxon inhabits many high mountainous areas, especially valleys (e.g., in 
the New Guinean Central Range, in the Andes, in the Alps and in the Himalayas), and uplands (e.g., in the East African Highlands), $\leq 3,000 \mathrm{~m}$ a.s.I. (see also Supporting Information Figure S1).

Discrete differences in morphological traits, including plumage coloration and body size, and in distribution have led to the identification of a variable number of species (from one to four) and subspecies (up to 36; for details, see Uva et al., 2018) worldwide. However, the most comprehensive molecular phylogeny published to date (Uva et al., 2018) failed to recognize most of the previously identified species/subspecies as independent taxonomic units. Although the taxonomy of the common barn owl species complex has not yet been determined fully (Uva et al., 2018), all the phylogenetic analyses (Aliabadian, Alaei-Kakhki, Mirshamsi, Nijman, \& Roulin, 2016; Uva et al., 2018; Wink, El-Sayed, Sauer-Gürth, \& Gonzalez, 2009) agreed that this group is split into three genetically distinct evolutionary lineages. Irrespective of their taxonomic level, from an evolutionary perspective these lineages can be considered as adaptive radiations occurring simultaneously in geographically separated regions: (a) the Western barn owl (T. alba), occurring in Africa, the Arabian Peninsula, the Middle East and Europe up to Southern Scandinavia; (b) the American barn owl (T. furcata), living from Southern Canada to Patagonia, including throughout the Caribbean, Galapagos and Hawaiian islands; and (c) the Eastern barn owl (T. javanica), inhabiting the part of Asia south of the Himalayan plateau and Australasia, including Tasmania and all the archipelagos in the Pacific Ocean (for further details, see Romano et al., 2019).

As recently reported, $T$. furcata and T. javanica lineages could be paraphyletic (Uva et al., 2018). Indeed, the former includes the ashy-faced owl (Tyto glaucops) from Hispaniola and smaller Antilles (the formerly identified subspecies Tyto glaucops nigrescens and Tyto glaucops insularis), and the latter includes the Sulawesi (Tyto rosenbergii) and the Taliabu (Tyto nigrobrunnea) masked owls, all taxa characterized by limited and insular distribution that were previously described as separate species using morphological criteria. Given that we cannot exclude the possibility that these three groups might be very recent cases of island adaptation, all the analyses described below were also carried out including the individuals belonging to these taxa.

\section{2 | Museum skins collection}

The bill length of 7,619 barn owl specimens, collected between 1809 and 2017 by 140 museums and private citizens (Supporting Information Appendix S1), was measured (expressed as millimetres $\times 10$; approximation of $.01 \mathrm{~mm}$ ) by the same experimenter (A. Roulin). To test whether the bill length measurement was reliable, we calculated its repeatability on 197 adults breeding in Switzerland, which were measured twice during the same year (between 1996 and 2011) by the same experimenter who collected data on museum specimens. The repeatability is very high (intraclass correlation coefficient $=.96 ; 95 \%$ confidence interval $=.95-.97)$, and measurement error is very low $(.049 \mathrm{~mm})$.
Collected specimens cover the entire range of distribution of the three evolutionary lineages of the barn owl species complex, and the total sample includes 3,902 Western, 2,525 American and 1,192 Eastern barn owls (Supporting Information Appendix S1, Figure S1). Bill length is a reliable proxy of the total bill surface (and body size; Roulin, Riols, Dijkstra, \& Ducrest, 2001; see below), and it has been used in most of the previous influential studies on beak size variation in birds (e.g., Symonds \& Tattersall, 2010).

When possible, the sex of the individual was recorded. Overall, data on 3,054 males, 3,270 females and 1,295 unsexed individuals were collected. Following a previous study using the same approach (Romano et al., 2019), all the analyses were run on the total sample of specimens (i.e., excluding the effect of sex in the models) and on a subsample of individuals for which the information about sex was available.

\subsection{Climatic and geographical data}

The geographical coordinates of the recovery site of each individual were reported (Supporting Information Figure S1). When the label reported a region (or small country) name, rather than a precise location, coordinates near the centre of the region were assigned to the individual. If different specimens were collected in the same area, slightly different coordinates (distance $1-5 \mathrm{~km}$ ) were assigned to each of them. This was done in order to consider all the individuals as separate observations, because they were collected in different years and because barn owls are basically territorial animals (for further details, see Romano et al., 2019).

For each latitude-longitude combination, climatic (temperature) and geographical (elevation) information were reported. Elevation data were extracted at a 30 arc-s spatial resolution from the International Centre for Tropical Agriculture site (http://srtm.csi.cgiar.org; Jarvis, Reuter, Nelson, \& Guevara, 2008), and temperature information was extracted at the same spatial resolution from the WordClim data repository (http://www.worldclim.org/) for the period 1970-2000 (for details, see Romano et al., 2019). Given that the barn owl is a resident species, spending the entire year within a few kilometres of its nest, the mean annual temperature and elevation over a radius of $20 \mathrm{~km}$ from the location where each specimen was collected were associated to each individual (for details, see Romano et al., 2019). The elevational range of the sampled locations is very similar between T. alba (minimum, -224 m; maximum, 4,099 m) and T. furcata (minimum, -66 m; maximum, $4,357 \mathrm{~m}$ ), whereas for $T$. javanica it is smaller than for the other two lineages (minimum, $-2 \mathrm{~m}$; maximum, 2,228 m). However, variation in bill size has often been associated with the minimum or the maximum annual temperature, rather than with the mean annual temperature (e.g., Danner \& Greenberg, 2015; Friedman et al., 2017; Greenberg, Danner, et al., 2012). Therefore, we also extracted information on the minimum and maximum temperatures recorded at the same $20 \mathrm{~km}$ radius scale.

We note that the timespan of temperature data does not coincide with the period when the specimens were collected (18092017). However, the large reduction in sample size (from 7,619 to 1,622 specimens) prevented us from carrying out the analyses on 
the subset of individuals collected only in the same timespan. In order to account for the variability in the year of collection of the specimens, we thus adopted a different approach. We repeated the analyses using the mean annual temperature recorded over the decade when each individual lived (i.e., when it was collected by the museum). Temperature information before 1970 was collected from PaleoView (Fordham et al., 2017) at a $2.5^{\circ} \times 2.5^{\circ}$ latitude-longitude spatial resolution, whereas temperature after 1969 was collected using the Climatic Research Unit dataset (TS3.10 Dataset; Harris, Jones, Osborn, \& Lister, 2014) at a $.5^{\circ} \times 5^{\circ}$ latitude-longitude spatial resolution. This was done because we could not find any climatic data repository reporting temperature information at higher spatial resolution for the entire period of the study. The 559 individuals for which the year of collection was not reported were associated with the average mean annual temperature recorded in their recovery location over the entire period spanning from the year when the first (i.e., 1809) to the last (i.e., 2017) specimens were collected. However, because of: (a) the low resolution of temperature data; (b) the use of different sources to extract these data; (c) the large positive correlation between current and past temperature recorded in the same locations (for details, see Romano et al., 2019); and (d) considering that the results were qualitatively similar, we chose to report in the main text the results obtained using temperature data collected between 1970 and 2000 at a very high resolution, as we did in a previous study (Romano et al., 2019). The results of the analyses in which each specimen was associated with the temperature recorded in the decade when it was alive are, however, reported in the Supporting Information.

\section{4 | Statistical analyses}

The analyses were performed using generalized least squares (GLS) methods accounting for spatial autocorrelation between data points, with the nlme package (Pinheiro, Bates, DebRoy, Sarkar, \& R Core Team, 2014) in R (v.3.5.1; R Core Team, 2018). Variation in bill size was tested separately for T. alba, T. furcata and T. javanica in three different sets of models that included as main predictors, respectively: (a) mean annual temperature; (b) minimum and maximum annual temperature; and (c) absolute latitude and elevation. A full model including all the independent variables was not performed because of the high correlation between temperature and absolute latitude $(r=-.85)$. In the latter models, a logarithmic conversion of elevation values was used in order to approximate to a normal distribution. Given that some recovery locations were below sea level (e.g., Israel or The Netherlands), the logarithmic conversion was performed after the addition of the most negative elevation value to each elevation value in order to generate all positive values and to maintain the absolute elevational difference among locations. Temperature and elevation values were also standardized within each evolutionary lineage to consider only the range of values to which each barn owl group was subjected during its adaptive radiation. This procedure was also chosen because it provides scale-independent estimates of the covariation between bill size and predictors and because it allows a better comparison between the results obtained on different lineages.

The size of the bill is known to vary allometrically according to the overall body size (Roulin et al., 2001). To account for this source of variation, and therefore to account for bill size relative to body size, in all the models we included "wing length" as an additional predictor. In addition, all the models were repeated using the ratio between bill length and wing length as a dependent variable. Results are always qualitatively similar, and we therefore show only the results obtained using the first described approach. We used wing length as a proxy for body size, following the vast majority of the studies investigating body size variation in birds (see e.g., a meta-analysis by Ashton, 2002; but for limitations of this approach, see e.g., Gosler \& Harper, 2000). In addition, and importantly, given that we relied only on museum specimens, wing length is the only available and reliable information on body size that it was possible to collect. However, all the analyses were also performed without accounting for body size to check for the effect of including wing length in the models.

Bill size (and body size) is also predicted to vary according to both the availability and the size of food resources. Therefore, it has generally been recognized that insular populations should be different in size from those living on continents (Lomolino, 2005), and this is also the case in our model system (Roulin \& Salamin, 2010). To account for this additional source of variation, in all the models a two-level factor indicating whether each specimen originated from a continent (including Australia; coded as zero) or from an island (coded as one) was included. Finally, given that bill size can be hypothesized to vary non-monotonically with temperature (see e.g., Greenberg \& Danner, 2012), we also included the quadratic term of temperature in the models, which was removed from final models because it was never significant (details not shown).

In all the analyses, a model-specific spatial correlation structure (Züur, leno, Walker, Saveliev, \& Smith, 2009) was added to account for spatial autocorrelation between each pair of data points (for details, see Romano et al., 2019). We ran models including both a Gaussian and an exponential correlation matrix, and selected the one to be included in the final model according to the associated Akaike information criterion (AIC). The correlation structures were realized with the CorRGaus/CorRExp procedure implemented in the $\mathrm{R}$ package ramps (Smith, Yan, \& Cowles, 2008) by setting the "range" value after examining the variogram of the residuals of each model performed, considering all the data points as independent observations (Züur et al., 2009). The "haversine" metric was used to set the great-circle distance between each pair of coordinates. When necessary, correlation matrices were also weighed by their associated nugget effect (i.e., a parameter indicating the variability observed between samples that are closely located). Finally, each resulting correlation matrix was converted into a correlation structure (corsym) in order to make it usable with a GLS procedure. Spatial independence of the residuals of the final models was checked by examining the variogram plots. A comparison between the AIC of each model before and after the inclusion of correlation matrix was also performed. In all cases, the final models showed no spatial dependence of residuals, and the AIC of each model decreased significantly (Supporting Information Table S1). 
Effect sizes of the associations between bill length and, respectively, temperature, absolute latitude and elevation were computed by repeating the analyses by standardizing all the variables, including the dependent variable. In such conditions, the regression coefficients are comprised between minus one and plus one and can be considered as semipartial correlations, which reflect the strength of the association between the dependent variable and each predictor (Schielzeth, 2010; S. Nakagawa, personal communication). This procedure was used to compare different models, in addition to a comparison between the difference in the AICs of each model before and after the inclusion of the predictor(s) of interest (e.g., mean annual temperature).

All the models described above were carried out on all the individuals (including unsexed ones) and only on the subset of specimens for which the sex was known. In the latter case, an additional dichotomic factor indicating the individual sex ( 1 = male; 2 = female) was added to the models, in addition to the interaction between sex and temperature to test for potential sex-related effects of temperature on bill length. Moreover, all the analyses were repeated including data of T. glaucops (113 specimens), nested within T. furcata, in addition to T. rosenbergii (48 specimens) and T. nigrobrunnea (one specimen), both nested in T. javanica. However, given the poor model fit for the models including $T$. rosenbergii and T. nigrobrunnea, in addition to the likelihood that paraphyletic groups might exhibit different allometric relationships between bill and body size, we excluded all three taxa for which there currently exists taxonomic uncertainty (details of analyses including these taxa are available upon request).

Finally, in order to provide a comprehensive picture of variation in bill size at the global scale, we also performed models including the same aforementioned predictors on data of the three barn owl lineages pooled together. These models included the additional effect "evolutionary lineage", in order to pool data belonging to the three distinct evolutionary units. The coefficients reported in the Results section refer to the analyses performed on all the individuals (including unsexed ones) excluding specimens of T. glaucops, T. rosenbergii and T. nigrobrunnea, but all the models performed on different subsamples of data always provided qualitatively similar results (details not shown for brevity).

\section{3 | RESULTS}

In all three lineages, bill length increased with increasing mean annual temperature recorded around the sites where specimens were collected (Table 1; Figure 1). This was the case also when the analyses were limited to the subsample of the "sexed" individuals (Supporting

TAB LE 1 Variation in bill length according to mean annual temperature and island versus mainland in the three lineages of the common barn owl group

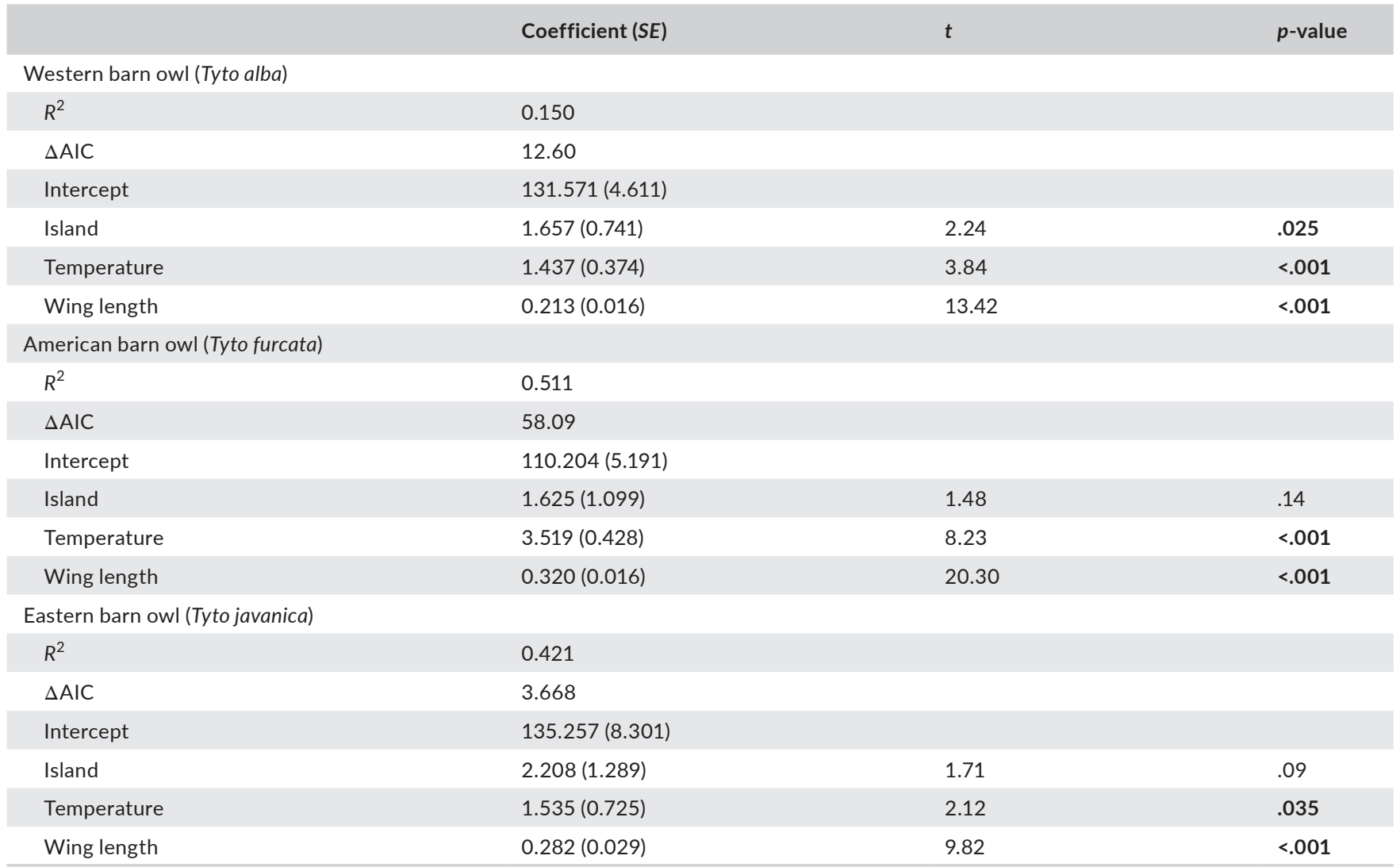

Note: Bold type indicates statistical significance. Residual degrees of freedom: T. alba $=3898 ;$ T. furcata $=2521 ;$ T. javanica $=1188 . R^{2}$ shows the variance explained by the models and the change in Akaike information criterion $(\triangle \mathrm{AIC})$ indicates the difference between the model including or excluding "Temperature". 


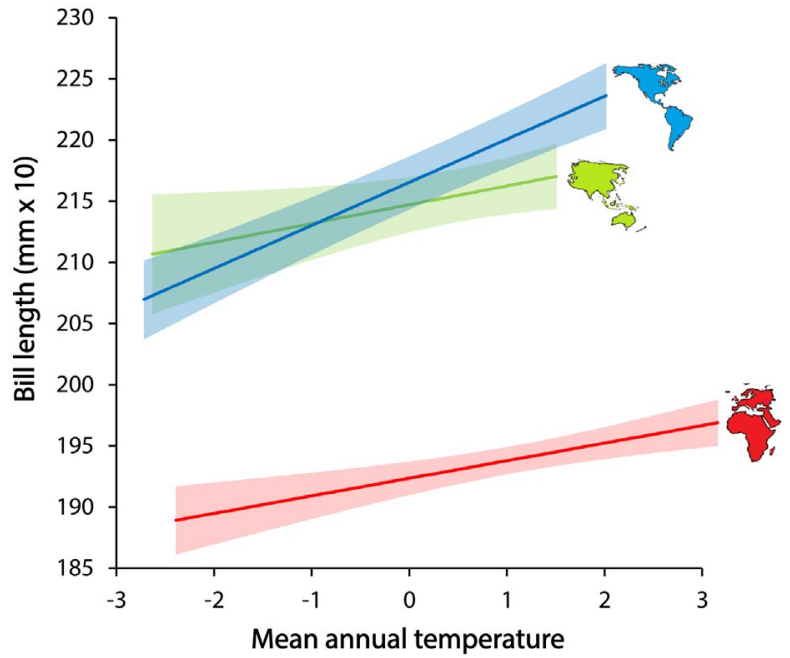

FIGURE 1 Relationship between mean annual temperature and bill length in the three lineages of the common barn owl group: the Western barn owl (Tyto alba; red line) the American barn owl (Tyto furcata; blue line) and the Eastern barn owl (Tyto javanica; green line). Regression lines and 95\% confidence intervals (coloured bands) from the models reported in Table 1 are shown. Values of mean annual temperature were standardized within each taxon to facilitate the comparison among the lineages [Colour figure can be viewed at wileyonlinelibrary.com]

Information Table S2) and when we used the mean annual temperature of the decades when each specimen was collected (Supporting Information Table S3). When we included the effect of the interaction between sex and temperature in the models, this term was never statistically significant (T. alba: $t=-1.61, p=.11$; T. furcata: $t=$ -1.32; $p=.19 ;$ T. javanica: $t=-.41, p=.69$ ), thus indicating a similar pattern of variation in bill length according to temperature in both sexes. The effect sizes of the relationship between temperature and bill length are moderate to medium depending on the barn owl lineage $(T$. alba $=.157 ;$. furcata $=.265 ;$. javanica $=.146)$.

Interestingly, in the models including minimum and maximum temperature rather than mean annual temperature, in all three lineages the minimum temperature was statistically significant (Supporting Information Table S4; effect sizes: T. alba = .100; T. furcata $=.198 ;$ T. javanica $=.194)$. In addition, maximum temperature positively predicted bill length only in T. furcata (Supporting Information Table S4; effect sizes: T. alba $=.067$; T furcata $=.127$; T. javanica $=-.023$ ).

The third set of analyses showed that in all the three lineages of the common barn owl there was a significant variation in beak size according to absolute latitude (Table 2). In particular, individuals displaying a larger beak were found close to the Equator rather than at higher latitudes (Figure 2). The effect sizes of this relationship were moderate to large depending on the barn owl lineage $(T$. alba $=-.217 ;$. furcata $=-.140 ; T$. javanica $=-.513)$. This pattern of variation in bill size according to latitude was similar in both hemispheres, as suggested by the lack of a statistically significant effect of the interaction between hemisphere and absolute latitude (all $|t|<1.69$, all $p>$.09). In addition, in $T$. furcata an effect of elevation was observed: bill size decreased at increasing elevation (Table 2; Figure 2). The effect sizes of the relationship between elevation and bill length were moderate in T. furcata (-.148) and negligible in both T. alba (-.051) and T. javanica (.010). Finally, and interestingly, in $T$. furcata a significant effect of the interaction between elevation and latitude emerged $(t=4.64, p<.001)$, whereas this was not the case for $T$. alba $(t=1.64, p=.10)$ and T. javanica ( $t=.15, p=.88$ ). As expected, in the American barn owl large-billed birds mostly occurred at lower elevation closer to the Equator, with bill length decreasing progressively at concomitant increasing latitude and elevation (Supporting Information Figure S2). The results were qualitatively similar when the analyses were

TAB LE 2 Variation in bill length according to absolute latitude, elevation and island versus mainland in the three lineages of the common barn owl group

\begin{tabular}{|c|c|c|c|}
\hline & Coefficient (SE) & $t$ & $p$-value \\
\hline \multicolumn{4}{|l|}{$\begin{array}{l}\text { Western barn owl } \\
\text { (Tyto alba) }\end{array}$} \\
\hline$R^{2}$ & 0.150 & & \\
\hline$\Delta \mathrm{AIC}$ & 4.78 & & \\
\hline Intercept & $136.859(4.677)$ & & \\
\hline Island & $1.510(0.729)$ & 2.07 & .038 \\
\hline Absolute latitude & $-0.132(0.036)$ & 3.66 & $<.001$ \\
\hline Elevation & $-0.461(0.276)$ & 1.67 & .10 \\
\hline Wing length & $0.212(0.016)$ & 13.36 & $<.001$ \\
\hline \multicolumn{4}{|l|}{$\begin{array}{l}\text { American barn owl } \\
\text { (Tyto furcata) }\end{array}$} \\
\hline$R^{2}$ & 0.507 & & \\
\hline$\Delta \mathrm{AIC}$ & 37.20 & & \\
\hline Intercept & $115.679(5.239)$ & & \\
\hline Island & 1.641 (1.087) & 1.51 & .13 \\
\hline Absolute latitude & $-0.156(0.070)$ & 2.22 & .027 \\
\hline Elevation & $-1.965(0.300)$ & 6.55 & $<.001$ \\
\hline Wing length & $0.317(0.016)$ & 19.95 & $<.001$ \\
\hline \multicolumn{4}{|l|}{$\begin{array}{l}\text { Eastern barn owl } \\
\text { (Tyto javanica) }\end{array}$} \\
\hline$R^{2}$ & 0.430 & & \\
\hline$\Delta \mathrm{AIC}$ & 15.523 & & \\
\hline Intercept & $151.974(8.740)$ & & \\
\hline Island & 0.661 (1.318) & 0.50 & .62 \\
\hline Absolute latitude & $-0.508(0.106)$ & 4.79 & $<.001$ \\
\hline Elevation & $0.107(0.277)$ & 0.38 & .70 \\
\hline Wing length & $0.264(0.029)$ & 9.16 & $<.001$ \\
\hline
\end{tabular}

Note: The effect of the interaction between absolute latitude and elevation is reported in the main text. Bold type indicates statistical significance. Residual degrees of freedom: $T$. alba $=3,897 ;$. furcat $a=2,520$; T. javanica $=1,187 . R^{2}$ shows the variance explained by the models, and the change in Akaike information criterion $(\triangle A I C)$ indicates the difference between the model including or excluding "Absolute latitude" and "Elevation". 

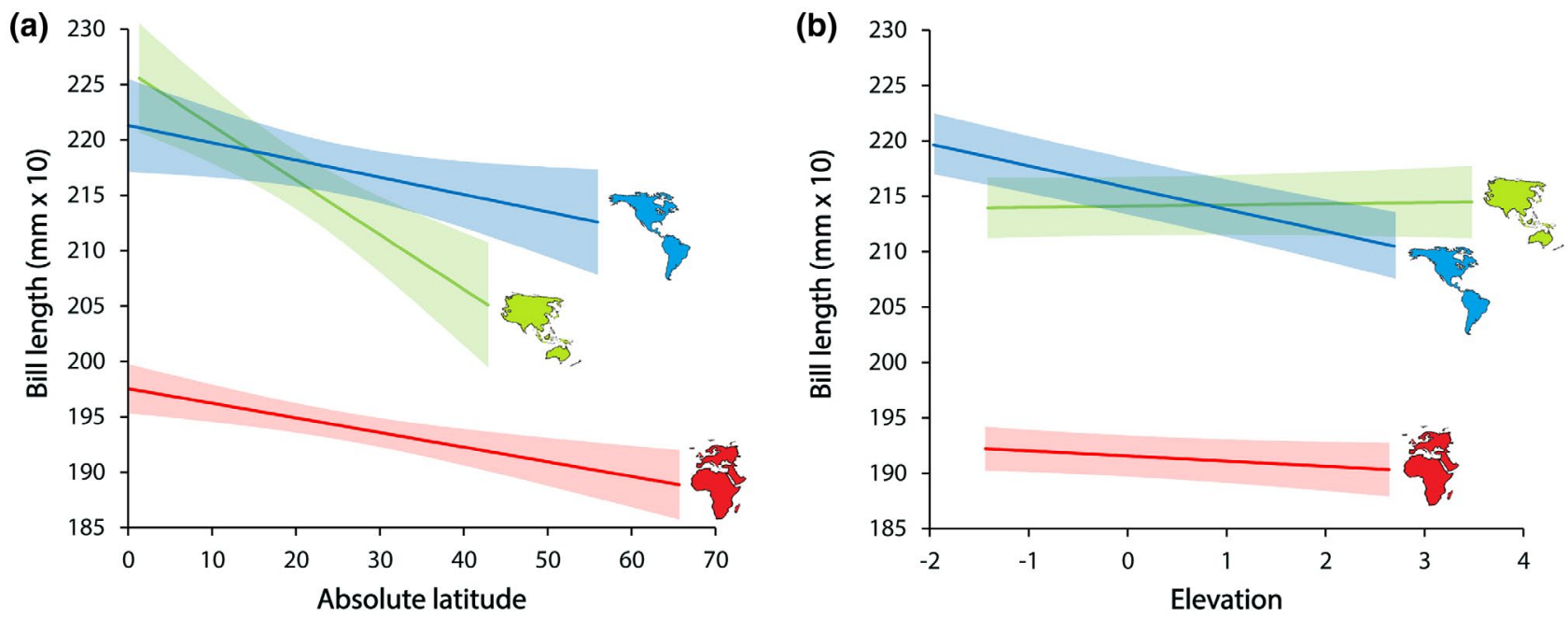

FIGURE 2 Relationship between absolute latitude and elevation and bill length in the three lineages of the common barn owl group. Upper panel: bill length according to absolute latitude; lower panel: bill length according to elevation. The Western barn owl (Tyto alba; red line); the American barn owl (Tyto furcate; blue line); the Eastern barn owl (Tyto javanica; green line). Regression lines and $95 \%$ confidence intervals (coloured bands) from the models reported in Table 2 are shown. Values of elevation were standardized within each taxon to facilitate the comparison among the lineages [Colour figure can be viewed at wileyonlinelibrary.com]

limited to the subsample of the "sexed" individuals (Supporting Information Table S2).

Qualitatively similar results were obtained using the ratio between bill length and wing length as a dependent variable (an example is given in Supporting Information Table S5; other details are available upon request).

When the analyses were performed without accounting for the effect of wing length, in T. alba the results were similar to those described above (temperature: $t=2.85, p=.004$, effect size: .135 ; absolute latitude: $t=-3.29, p=.001$, effect size: -.209 ; elevation: $t=-1.01, p=.32$, effect size: -.032). In T. furcata, the effects of temperature and elevation were smaller but still statistically significant (temperature: $t=4.39$, $p<.001$, effect size: 0.160; elevation: $t=-3.14, p=.002$, effect size: -.093), whereas the latitudinal trend disappeared ( $t=-0.07, p=.95$, effect size: -.008). However, the effect of the interaction between absolute latitude and elevation was confirmed ( $t=1.96, p=.05$ ). In T. javanica, the effect of temperature became statistically non-significant ( $t=0.14, p=.89$, effect size: .010). However, a latitudinal variation in bill length was confirmed (absolute latitude: $t=-4.70, p \leq .001$, effect size: -.590; elevation: $t=1.51, p=.13$, effect size: .044$)$.

The analyses performed on data of all the lineages pooled together showed that bill size increased with increasing temperature (mean: $2.651 \pm .298, t=8.88, p<.001$; minimum: $1.815 \pm .354$, $t=5.13, p<.001$; maximum: $1.267 \pm .281, t=4.50, p<.001)$ and with decreasing absolute latitude $(-0.175 \pm 0.035, t=5.05, p<.001)$ and elevation $(-.953 \pm .167, t=5.71, p<.001)$.

\section{4 | DISCUSSION}

In the present study, we showed that the size of the barn owl bill is linked to the temperature recorded in the environments where birds live. In particular, individuals inhabiting in colder environments display relatively smaller bills compared with those occurring in warmer climates. This is consistently the case for populations living in the Afro-Palaearctic region, in the Americas and in Australasia. Importantly, although the specimens used in the present study were collected over a large timespan, our findings are not confounded by the temporal variation in temperature occurring at different magnitude across the globe, because very similar findings were obtained when each specimen was associated with the temperature recorded in the decade when it was alive. On the whole, these results are coherent with the prediction of Allen's rule (Allen, 1876) and provide evidence of intraspecific variation in bill size according to temperature at the global scale. The observation that a similar association between beak size and temperature occurs in geographically separated, but genetically closely related, evolutionary lineages is consistent with the hypothesis that this trait is, at least in part, convergently selected for body heat maintenance depending on the thermal environment.

Interestingly, in all three lineages the minimum temperature predicts bill length better than maximum temperature. Together with the observation that the quadratic effect of temperature was never significant, this finding is compatible with the nocturnal habits of the barn owl, which is mainly active in the coolest part of the day and therefore should not be subjected to overheating. The nocturnal behaviour of the barn owl could also be the reason why our statistical models explain a small to medium amount of variance in bill length according to temperature. In addition, the investigation of a single taxon displaying a rather conserved morphology should limit the expected variation in bill size compared with comparative analyses performed on different species displaying a large variability in bill shape (Symonds \& Tattersall, 2010). Finally, it is important to note that, as in all raptors, the 
evolution of the shape and size of the barn owl bill was probably constrained by the diet, which is invariably based on small mammals across the globe, thus further limiting its potential thermoregulatory function. We note, however, that the values of variance explained by our models are similar or even larger than those usually reported by evo-ecological studies (see e.g., Low-Décarie, Chivers, \& Granados, 2014; Møller \& Jennions, 2002).

This convergent pattern of evolution of larger bills in warmer climates among the three different barn owl lineages seems to be driven mainly by a latitudinal variation in temperature. Indeed, individuals of T. alba, T. furcata and T. javanica living at higher latitudes display smaller bills compared with their conspecifics occurring closer to the Equator. The observation that this was the case irrespective of the hemisphere (i.e., no significant effect of the interaction between absolute latitude and hemisphere was observed in all the lineages) suggests the occurrence of a very general macroecological pattern of spatial distribution in bill size across the globe. Interestingly, in the American lineage, we also observed an elevational cline, with individuals inhabiting higher elevations showing a significantly smaller beak compared with those living at elevations closer to sea level. Another piece of evidence showing an association between temperature and bill size was provided by the significant effect of the interaction between latitude and elevation in the American barn owl, with small-billed birds occurring mainly at high elevations far from the Equator. Why this pattern was observed only in T. furcata is a matter of speculation. A possible interpretation rests on the observation that the highest mountain ranges in the Americas (i.e., Andes, Rocky Mountains and Sierra Madre Occidental) cover almost the entire latitudinal range of distribution of $T$. furcata (i.e., they are mostly perpendicular to Equator), whereas this is not the case for Europe, Africa, South-East Asia and Australia. A change in bill size according to the concomitant variation in latitude and elevation might therefore be expected in the Americas rather than in the Afro-Palaearctic region or Australasia.

The comparison between different models suggests that the temperature is the main driver of bill size variation in T. alba and T. furcata, because the climatic models perform better than the geographical ones. In addition, the effect of mean temperature is always larger than that of minimum temperature, probably because this information integrates the climatic conditions experienced by the individuals better during the entire year. This is not surprising, because the barn owl is a resident species, spending the circannual cycle in the same area. However, the relatively low variance explained by the models of T. alba also indicates that other selective pressures not considered here substantially contribute to the generation of the spatial variation in bill length observed in this lineage. In contrast, a different story seems to emerge for T. javanica, in which, although the temperature (mean and minimum) is always a significant predictor of bill length, the main driver of its geographical variation is latitude. Given the correlative nature of our analyses and the many functions of the bill, we cannot exclude the possibility that the patterns observed might also have been affected by some untested variables, such as local diet or prey size, which can vary geographically in a manner similar to temperature. This should be the case especially for T. javanica. The investigation of barn owl diet across the globe can thus constitute an interesting follow-up to the present study.

Another aspect that deserves attention is the observation that the effect sizes of the models including wing length as predictor are systematically larger than the corresponding ones excluding this effect. Such an effect is particularly marked in T. javanica, for which the effect of temperature disappeared when we did not control for body size. Although absolute bill length is significantly climate dependent in T. alba and T. furcata, this finding thus indicates that the main temperature effect is on the size of the bill relative to body size, rather than on the absolute bill length. This is consistent with previous studies on other birds (Campbell-Tennant et al., 2015; Friedman et al., 2017; Greenberg, Cadena, et al., 2012; Greenberg, Danner, et al., 2012; Johansson et al., 1998; Symonds \& Tattersall, 2010).

The structure of the avian bill is one of the best textbook cases of evolution in response to different selective pressures (Badyaev et al., 2008; Podos \& Nowicki, 2004; Willson et al., 1975), although it mostly reflects feeding habits, even among different populations of the same species (Grant \& Grant, 1995; Smith, 1987). However, it is well known that the tissue underlying the outer keratinaceous layer of the bill is highly vascularized (Lucas \& Stettenheim, 1972), thus allowing birds to disperse a substantial amount of body heat (Greenberg, Cadena, et al., 2012; Scott et al., 2008; Symonds \& Tattersall, 2010; Tattersall et al., 2009, 2017). Like other poorly insulated animal appendages, such as the ear pinnae of hares (Hill, Christian, \& Veghte, 1980; Stevenson, 1986), the flippers of pinnipeds (Whittow, Matsuura, \& Lin, 1972) or the legs and the tails in birds and mammals (e.g., Baudinette, Loveridge, Wilson, Mills, \& Schmidt-Nielsen, 1976; Fooden \& Albrecht, 1999), the primary function of the avian bill can thus have been co-opted for thermoregulatory purposes. This is the case also for raptor species, whose bill size and shape evolved primarily as adaptations to promote the hunting and consumption of animal prey, as shown by the present and previous studies (Gehlbach, 2003; Johansson et al., 1998).

The only available information about the heritability of bill size in our model system was collected in a Swiss population $\left(h^{2}=.62\right.$; Roulin, 2006). According to previous studies on other avian species (Keller, Grant, Grant, \& Petren, 2001; Smith \& Dhondt, 1980), the study of Roulin (2006) provided evidence that bill length is determined by a strong genetic component. It is therefore likely that different sizes of the bill have been selected under different temperature regimes rather than having emerged as a consequence of a climatic effect on bill development during ontogeny. Nevertheless, the possibility that a peculiar bill size arose in different populations as a plastic trait driven by the temperature to which barn owls were exposed during development/rearing cannot be discarded fully. In fact, it has been shown that birds reared in an experimental cold environment developed smaller bills than related individuals reared in warmer conditions (Burness, Huard, Malcolm, \& Tattersall, 2013; see also James, 1983). Natural selection positively favouring individuals 
depending on the bill size in different thermal environments and phenotypic plasticity in the development of the bill in different temperature conditions might thus have acted together to determine the pattern of geographical variation documented in the present study.

Spatial and temporal patterns of variation in morphological traits have recently attracted increasing scientific attention because of potentially predictable response by organisms to climate change. Indeed, an increasing number of studies have provided evidence of an association between temporal variation in morphological traits and the concomitant increase in temperature (e.g., Møller, Erritzøe, \& Dongen, 2018), thus suggesting that it might be considered a general effect of global warming (e.g., Gardner, Peters, Kearney, Joseph, \& Heinsohn, 2011; Sheridan \& Bickford, 2011; Van Buskirk, Mulvihill, \& Leberman, 2010). However, although an increase in the frequency of large-billed individuals should be expected in regions where annual temperature is increasing, to the best of our knowledge, only one study has found evidence of such a temporal trend in bill size (Campbell-Tennant et al., 2015). In the light of our study, providing evidence of convergent evolution of bill size in line with the prediction of Allen's rule during three simultaneous adaptive radiations, we encourage further research on other species to investigate whether the changing thermal environments consequent to the current global warming are imposing a general response in bird bill size at the worldwide scale.

\section{ACKNOWLEDGMENTS}

We are indebted to all the museum curators who permitted us to measure barn owl skins. We thank Professor Shinichi Nakagawa for statistical advice on the calculation of effect size. We are also grateful to two anonymous reviewers and Dr Brian Olsen for constructive comments on a previous version of the manuscript. The present study was funded by the Swiss National Science Foundation, the American Natural History Museum in New York, the Swiss Academy of Sciences, the "Fondation Agassiz" and "Fondation du 450eme anniversaire" of the University of Lausanne, and the Basler Stiftung fur biologische Forschung.

\section{AUTHOR CONTRIBUTIONS}

A. Romano and A. Roulin conceived the study; A. Roulin collected the data; A. Romano and R. Séchaud performed the statistical analyses; A. Romano drafted the manuscript; and all the authors contributed to the final version of the paper.

\section{DATA AVAILABILITY}

The dataset analysed in this study are available via Dryad: https:// doi.org/10.5061/dryad.79ck1tm

\section{ORCID}

Andrea Romano (iD https://orcid.org/0000-0002-0945-6018

Alexandre Roulin (iD https://orcid.org/0000-0003-1940-6927

\section{REFERENCES}

Aliabadian, M., Alaei-Kakhki, N., Mirshamsi, O., Nijman, V., \& Roulin, A. (2016). Phylogeny, biogeography, and diversification of barn owls (Aves: Strigiformes). Biological Journal of the Linnean Society, 119, 904-918. https://doi.org/10.1111/bij.12824

Allen, J. A. (1876). Geographical variation among North American mammals, especially in respect to size. Bulletin of the United States Geological and Geographical Survey of the Territories, 2, 309-344.

Ashton, K. G. (2002). Patterns of within-species body size variation of birds: Strong evidence for Bergmann's rule. Global Ecology and Biogeography, 11, 505-523. https://doi.org/10.1046/j.1466-822X.2002.00313.x

Atkinson, D., \& Sibly, R. M. (1997). Why are organisms usually bigger in colder environments? Making sense of a life history puzzle. Trends in Ecology and Evolution, 12, 235-239. https://doi.org/10.1016/ S0169-5347(97)01058-6

Badyaev, A. V., Young, R. L., Oh, K. P., \& Addison, C. (2008). Evolution on a local scale: Developmental, functional, and genetic bases of divergence in bill form and associated changes in song structure between adjacent habitats. Evolution, 62, 1951-1964. https://doi. org/10.1111/j.1558-5646.2008.00428.x

Baudinette, R. V., Loveridge, J. P., Wilson, K. J., Mills, C. D., \& SchmidtNielsen, K. N. U. T. (1976). Heat loss from feet of herring gulls at rest and during flight. American Journal of Physiology-Legacy Content, 230, 920-924. https://doi.org/10.1152/ajplegacy.1976.230.4.920

Bergmann, C. (1847). Ueber die Verhältnisse der Wärmeökonomie der Thiere zu ihrer Grösse. Göttinger Studien, 1, 595-708.

Bunn, D. S. (1972). Regular daylight hunting by Barn Owls. British Birds, 65, 26-30.

Burness, G., Huard, J. R., Malcolm, E., \& Tattersall, G. J. (2013). Posthatch heat warms adult beaks: Irreversible physiological plasticity in Japanese quail. Proceedings of the Royal Society B: Biological Sciences, 280, 20131436.

Campbell-Tennant, D. J., Gardner, J. L., Kearney, M. R., \& Symonds, M. R. (2015). Climate-related spatial and temporal variation in bill morphology over the past century in Australian parrots. Journal of Biogeography, 42, 1163-1175. https://doi.org/10.1111/jbi.12499

Chown, S. L., \& Gaston, K. J. (2010). Body size variation in insects: A macroecological perspective. Biological Reviews, 85, 139-169. https://doi. org/10.1111/j.1469-185X.2009.00097.x

Danner, R. M., \& Greenberg, R. (2015). A critical season approach to Allen's rule: Bill size declines with winter temperature in a cold temperate environment. Journal of Biogeography, 42, 114-120. https:// doi.org/10.1111/jbi.12389

Fooden, J., \& Albrecht, G. H. (1999). Tail-length evolution in fascicularisgroup macaques (Cercopithecidae: Macaca). International Journal of Primatology, 20, 431-440.

Fordham, D. A., Saltré, F., Haythorne, S., Wigley, T. M., Otto-Bliesner, B. L., Chan, K. C., \& Brook, B. W. (2017). PaleoView: A tool for generating continuous climate projections spanning the last 21,000 years at regional and global scales. Ecography, 40, 1348-1358. https://doi. org/10.1111/ecog.03031

Friedman, N. R., Harmáčková, L., Economo, E. P., \& Remeš, V. (2017). Smaller beaks for colder winters: Thermoregulation drives beak size evolution in Australasian songbirds. Evolution, 71, 2120-2129. https ://doi.org/10.1111/evo.13274

Gardner, J. L., Peters, A., Kearney, M. R., Joseph, L., \& Heinsohn, R. (2011). Declining body size: A third universal response to warming? Trends in Ecology and Evolution, 26, 285-291. https://doi.org/10.1016/j. tree.2011.03.005

Gehlbach, F. R. (2003). Body size variation and evolutionary ecology of Eastern and Western screech-owls. The Southwestern Naturalist, 48, 70-80. https://doi.org/10.1894/0038-4909(2003)048<0070: BSVAEE > 2.0.CO;2

Gosler, A. G., \& Harper, D. G. C. (2000). Assessing the heritability of body condition in birds: A challenge exemplified by the great tit Parus 
major L. (Aves). Biological Journal of the Linnean Society, 71, 103-117. https://doi.org/10.1111/j.1095-8312.2000.tb01245.x

Grant, P. R., \& Grant, B. R. (1995). Predicting microevolutionary responses to directional selection on heritable variation. Evolution, 49, 241-251. https://doi.org/10.1111/j.1558-5646.1995.tb02236.x

Greenberg, R., \& Danner, R. (2012). The influence of the California marine layer on bill size in a generalist songbird. Evolution, 66, 38253835. https://doi.org/10.1111/j.1558-5646.2012.01726.x

Greenberg, R., Cadena, V., Danner, R. M., \& Tattersall, G. (2012). Heat loss may explain bill size differences between birds occupying different habitats. PLoS ONE, 7, e40933. https://doi.org/10.1371/journal. pone.0040933

Greenberg, R., Danner, R., Olsen, B., \& Luther, D. (2012). High summer temperature explains bill size variation in salt marsh sparrows. Ecography, 35, 146-152. https://doi.org/10.1111/j.1600-0587.2011.07002.x

Harris, I., Jones, P. D., Osborn, T. J., \& Lister, D. H. (2014). Updated highresolution grids of monthly climatic observations - the CRU TS3.10 dataset. International Journal of Climatology, 34, 623-642. https://doi. org/10.1002/joc.3711

Hill, R. W., Christian, D. P., \& Veghte, J. H. (1980). Pinna temperature in exercising jackrabbits, Lepus californicus. Journal of Mammalogy, 61, 30-38. https://doi.org/10.2307/1379954

James, F. C. (1983). Environmental component of morphological differentiation in birds. Science, 221, 184-186. https://doi.org/10.1126/ science.221.4606.184

Jarvis, A., Reuter, H. I., Nelson, A., \& Guevara, E. (2008). Hole-filled seamless SRTM data V4, International Centre for Tropical Agriculture (CIAT). Retrieved from http://srtm.csi.cgiar.org

Johansson, C., Linder, E., Hardin, P., \& White, C. (1998). Bill and body size in the peregrine falcon, north versus south: Is size adaptive? Journal of Biogeography, 25, 265-273. https://doi. org/10.1046/j.1365-2699.1998.252191.x

Keller, L. F., Grant, P. R., Grant, B. R., \& Petren, K. (2001). Heritability of morphological traits in Darwin's finches: Misidentified paternity and maternal effects. Heredity, 87, 325-336. https://doi. org/10.1046/j.1365-2540.2001.00900.x

König, C., \& Weick, W. (2008). Owls. A guide to the owls of the world (2nd ed.). London, UK: Christopher Helm.

LaBarbera, M. (1989). Analyzing body size as a factor in ecology and evolution. Annual Review of Ecology and Systematics, 20, 97-117. https:// doi.org/10.1146/annurev.es.20.110189.000525

Laiolo, P., \& Rolando, A. (2001). Ecogeographic correlates of morphometric variation in the red-billed chough Pyrrhocorax pyrrhocorax and the alpine chough Pyrrhocorax graculus. Ibis, 143, 602-616.

Lomolino, M. V. (2005). Body size evolution in insular vertebrates: Generality of the island rule. Journal of Biogeography, 32, 1683-1699. https://doi.org/10.1111/j.1365-2699.2005.01314.x

Low-Décarie, E., Chivers, C., \& Granados, M. (2014). Rising complexity and falling explanatory power in ecology. Frontiers in Ecology and Environment, 12, 412-418. https://doi.org/10.1890/130230

Lucas, A. M., \& Stettenheim, P. R. (1972). Avian anatomy: Integument. I \& II. Agriculture handbook 362. Washington, DC: USDA.

Machado, A. P., Clément, L., Uva, V., Goudet, J., \& Roulin, A. (2018). The Rocky Mountains as a dispersal barrier between barn owl (Tyto alba) populations in North America. Journal of Biogeography, 45, 1288-1300.

Mayr, E. (1956). Geographical character gradients and climatic adaptation. Evolution, 10, 105-108. https://doi.org/10.1111/j.1558-5646.1956. tb02836.x

Meiri, S. (2011). Bergmann's Rule - what's in a name? Global Ecology and Biogeography, 20, 203-207. https://doi.org/10.1111/j.14668238.2010.00577.x

Møller, A. P., \& Jennions, M. D. (2002). How much variance can be explained by ecologists and evolutionary biologists? Oecologia, 132, 492-500. https://doi.org/10.1007/s00442-002-0952-2
Møller, A. P., Erritzøe, J., \& Van Dongen, S. (2018). Body size, developmental instability, and climate change. Evolution, 72, 2049-2056. https://doi.org/10.1111/evo.13570

Nudds, R. L., \& Oswald, S. A. (2007). An interspecific test of Allen's rule: Evolutionary implications for endothermic species. Evolution, 61, 2839-2848. https://doi.org/10.1111/j.1558-5646.2007. 00242.x

Olson, V. A., Davies, R. G., Orme, C. D. L., Thomas, G. H., Meiri, S., Blackburn, T. M., ... Bennett, P. M. (2009). Global biogeography and ecology of body size in birds. Ecology Letters, 12, 249-259. https:// doi.org/10.1111/j.1461-0248.2009.01281.x

Pavlovic, G., Weston, M. A., \& Symonds, M. R. (2019). Morphology and geography predict the use of heat conservation behaviours across birds. Functional Ecology, 33, 286-296. https://doi. org/10.1111/1365-2435.13233

Pinheiro, J., Bates, D., DebRoy, S., Sarkar, D., \& R Core Team. (2014). Nlme: Linear and nonlinear mixed effects models. R package version 3.

Podos, J., \& Nowicki, S. (2004). Beaks, adaptation, and vocal evolution in Darwin's finches. AlBS Bulletin, 54, 501-510.

R Core Team. (2018). R: A language and environment for statistical computing. Vienna, Austria: R Foundation for Statistical Computing. Retrieved from https://www.R-project.org/

Romano, A., Séchaud, R., Hirzel, A. H., \& Roulin, A. (2019). Climatedriven convergent evolution of plumage colour in a cosmopolitan bird. Global Ecology and Biogeography, 28, 496-507. https://doi. org/10.1111/geb.12870

Roulin, A. (2006). Linkage disequilibrium between a melaninbased colour polymorphism and tail length in the barn owl. Biological Journal of the Linnean Society, 88, 475-488. https://doi. org/10.1111/j.1095-8312.2006.00636.x

Roulin, A., \& Salamin, N. (2010). Insularity and the evolution of melanism, sexual dichromatism and body size in the worldwide-distributed barn owl. Journal of Evolutionary Biology, 23, 925-934. https://doi. org/10.1111/j.1420-9101.2010.01961.x

Roulin, A., Riols, C., Dijkstra, C., \& Ducrest, A. L. (2001). Female plumage spottiness signals parasite resistance in the barn owl (Tyto alba). Behavioral Ecology, 12, 103-110. https://doi.org/10.1093/oxfordjour nals.beheco.a000371

Ryeland, J., Weston, M. A., \& Symonds, M. R. (2017). Bill size mediates behavioural thermoregulation in birds. Functional Ecology, 31, 885-893. https://doi.org/10.1111/1365-2435.12814

Salewski, V., \& Watt, C. (2017). Bergmann's rule: A biophysiological rule examined in birds. Oikos, 126, 161-172. https://doi.org/10.1111/ oik.03698

Schielzeth, H. (2010). Simple means to improve the interpretability of regression coefficients. Methods in Ecology and Evolution, 1, 103-113. https://doi.org/10.1111/j.2041-210X.2010.00012.x

Scott, G. R., Cadena, V., Tattersall, G. J., \& Milsom, W. K. (2008). Body temperature depression and peripheral heat loss accompany the metabolic and ventilatory responses to hypoxia in low and high altitude birds. The Journal of Experimental Biology, 211, 1326-1335. https://doi.org/10.1242/jeb.015958

Sheridan, J. A., \& Bickford, D. (2011). Shrinking body size as an ecological response to climate change. Nature Climate Change, 1, 401-406. https://doi.org/10.1038/nclimate1259

Smith, B. J., Yan, J., \& Cowles, M. K. (2008). Unified geostatistical modeling for data fusion and spatial heteroskedasticity with $\mathrm{R}$ package ramps. Journal of Statistical Software, 25, 1-21.

Smith, F. A., \& Lyons, S. K. (2011). How big should a mammal be? A macroecological look at mammalian body size over space and time. Philosophical Transactions of the Royal Society B: Biological Sciences, 366, 2364-2378. https://doi.org/10.1098/rstb.2011.0067

Smith, J. N. M., \& Dhondt, A. (1980). Experimental confirmation of heritable morphological variation in a natural population of 
songsparrows. Evolution, 34, 1155-1158. https://doi.org/10.1111/ j.1558-5646.1980.tb04058.x

Smith, T. B. (1987). Bill size polymorphism and intraspecific niche utilization in an African finch. Nature, 329, 717-719. https://doi.org/ 10.1038/329717a0

Stevenson, R. D. (1986). Allen's rule in North American rabbits (Sylvilagus) and hares (Lepus) is an exception, not a rule. Journal of Mammalogy, 67, 312-316. https://doi.org/10.2307/1380884

Symonds, M. R., \& Tattersall, G. J. (2010). Geographical variation in bill size across bird species provides evidence for Allen's rule. The American Naturalist, 176, 188-197. https://doi.org/10.1086/653666

Tattersall, G. J., Andrade, D. V., \& Abe, A. S. (2009). Heat exchange from the toucan bill reveals a controllable vascular thermal radiator. Science, 325, 468-470. https://doi.org/10.1126/science.1175553

Tattersall, G. J., Arnaout, B., \& Symonds, M. R. (2017). The evolution of the avian bill as a thermoregulatory organ. Biological Reviews, 92, 1630-1656. https://doi.org/10.1111/brv.12299

Uva, V., Päckert, M., Cibois, A., Fumagalli, L., \& Roulin, A. (2018). Comprehensive molecular phylogeny of barn-owls and relatives (Family: Tytonidae). Molecular Phylogenetics and Evolution, 125, 127-137.

Van Buskirk, J., Mulvihill, R. S., \& Leberman, R. C. (2010). Declining body sizes in North American birds associated with climate change. Oikos, 119, 1047-1055. https://doi.org/10.1111/j.1600-0706.2009.18349.x

Whittow, G. C., Matsuura, D. T., \& Lin, Y. C. (1972). Temperature regulation in the California sea lion (Zalophus californianus). Physiological Zoology, 45, 68-77. https://doi.org/10.1086/physzool.45.1.30155928

Willson, M. F., Karr, J. R., \& Roth, R. R. (1975). Ecological aspects of avian bill-size variation. The Wilson Bulletin, 87, 32-44.

Wink, M., El-Sayed, A.-A., Sauer-Gürth, H., \& Gonzalez, J. (2009). Molecular phylogeny of owls (Strigiformes) inferred from DNA sequences of the mitochondrial cytochrome $b$ and the nuclear RAG-1 gene. Ardea, 97, 581-591.

Züur, A., leno, E., Walker, N., Saveliev, A., \& Smith, G. (2009). Mixed effects models and extensions in ecology with R. Statistics for biology and health. New York, NY: Springer.

\section{BIOSKETCH}

The main goal of the research group led by Alexandre Roulin is to understand the role of natural and sexual selection in the evolution and maintenance of genetic and phenotypic variation in different morphological and chromatic traits and in their covariation by combining disciplines of evolutionary ecology, biogeography, behavioural ecology, genetics and population genetics/genomics. Specific aims of our research are to determine the adaptive function of alternative phenotypes, to identify how ecological, social and physiological factors influence and maintain inter-individual variation in melanin-based coloration and the other associated phenotypic traits, and to disclose the mechanisms favouring the high adaptability to different environmental conditions of this cosmopolitan raptor.

\section{SUPPORTING INFORMATION}

Additional supporting information may be found online in the Supporting Information section at the end of the article.

How to cite this article: Romano A, Séchaud R, Roulin A. Geographical variation in bill size provides evidence for Allen's rule in a cosmopolitan raptor. Global Ecol Biogeogr. 2020;29:65-75. https://doi.org/10.1111/geb.13007 